\title{
Unilateral Lung Aplasia Presenting with Acute Respiratory Distress Possibly due to milk aspiration in Young Toddler
}

\author{
Choudhury $\mathbf{J}^{1}$, Routray $\mathrm{SS}^{2}$, Biswal D ${ }^{3}$, Rout $\mathrm{K}^{4}$, Pradhan $\mathrm{K}^{5}$, Mishra $\mathrm{D}^{6}$ \\ ${ }^{1}$ Dr Jasashree Choudhury, Associate Professor, IMS \& SUM Hospital, Bhubneshwar, Odisha, ${ }^{2}$ Dr Sidharth Sraban \\ Routray*, Assistant Professor , ${ }^{3}$ Dr Debadas Biswal*, Assistant professor, ${ }^{4}$ Dr Khagaswar Rout*, Assistant Professor, ${ }^{5} \mathrm{Dr}$ \\ Kamalakanta Pradhan*, Assistant professor, ${ }^{6}$ Dr Debasis Mishra*, Senior resident. *All are affiliated to Department of \\ anaesthesiology and critical care, SCB Medical College, Hospital, Cuttack, Odisha, India
}

Address of Correspondence - Dr Jasashree Choudhury, E-mail: drjasashree@gmail.com

\begin{abstract}
A 13 month female child with h/o recurrent respiratory tract infection developed cough and breathlessness nearly 30 min after breastfeeding. Chest x-ray showed homogeneously opaque right hemi thorax with hyperlucency of left lung field suggestive of lung agenesis without any features of foreign body. Bronchoscopy revealed oedematous mucosa, thick bronchial secretions, mucus plug and white coagulates (apparently from milk) which were removed from left bronchus; trachea continued as left main bronchus without any stenosis or compression with absent right bronchus. Pulmonary agenesis was confirmed by CT scan in the post-operative period. The child made full recovery.
\end{abstract}

Key words: Lung aplasia, Respiratory distress, Recurrent respiratory tract infection.

\section{Introduction}

Lung aplasia is often associated with acute respiratory distress and has a high mortality rate as this is usually associated with anomalies like coarctation of aorta, aortic stenosis, transposition of great vessels and septa defects [1]. Fifty percent born with pulmonary aplasia are stillborn or die within the first five years of life [2]. Bilateral congenital pulmonary agenesis is a rare lethal anomaly, first described by Morgagni [3]. In unilateral lung agenesis, the trachea continues directly into the main bronchus of the normally developed lung. Foreign body (FB) inhalation is a potentially life threatening event, in these patients. A small reduction in airway radius due to oedema will result in a large increase in resistance to air flow. Hypoxia may rapidly occur because of high oxygen consumption of infants. [4] Bronchoscopy is done for a wide variety of diagnostic and therapeutic procedures. Bronchoscopic procedures poses a number of challenges in paediatric age group and requires the paediatrician to be fully familiar with airway and medical management.[5] We describe a case of right lung agenesis presenting with respiratory distress due to aspiration of breast milk which was misdiagnosed as a case of foreign body bronchus.

\section{Case report}

A 13-month-old female child, weighing $10 \mathrm{~kg}$, presented with severe respiratory distress and peripheral cyanosis. The child had breast-feeding about 2 hours before onset of symptoms. She started to cough and became breathless 30 min after feeding. She had past history of recurrent respiratory tract infections. On examination, the child had cough, dyspnea, and tachypnea with peripheral cyanosis. Her heart rate was $140 / \mathrm{min}$, respiratory rate was $45 / \mathrm{min}$ and oxygen saturation was $85 \%$ in room air. Air entry was absent on right side of chest while heezing was noted on left side of chest. Chest wall was bilaterally symmetrical without any skeletal deformity. Plain X-ray chest showed homogenously opaque right hemithorax with mediastinal shift and hyperlucency of left lung field. Any definite diagnosis could not be made, and emergency bronchoscopy was planned under general anaesthesia.

Manuscript received: $7^{\text {th }}$ Oct 2014

Reviewed: $16^{\text {th }}$ Oct 2014

Author Corrected; $29^{\text {th }}$ Oct 2014

Accepted for Publication: $4^{\text {th }}$ Nov 2014 


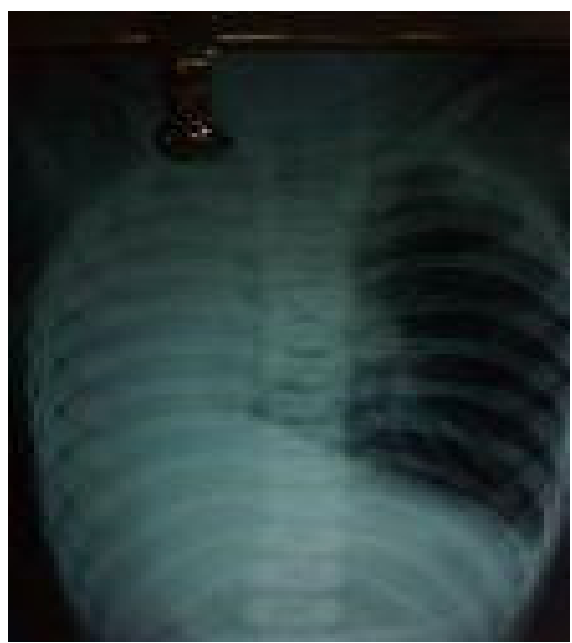

Figure1: Chest $\mathrm{x}$-ray showing opaque right hemithorax and hyperlucent left hemithorax

Bronchoscopy revealed oedematous mucosa, thick bronchial secretions, mucus plug and white coagulates (apparently from milk) which were removed from left bronchus. Bronchoscopy also revealed that trachea continued as left main bronchus without any stenosis or compression with absent right bronchus. A $4 \mathrm{~mm}$ plain oral endotracheal tube was placed after bronchoscope removal, and the lung was well expanded. Air entry improved on the left side. The child improved dramatically in the postoperative period.

Medications included hydrocortisone $50 \mathrm{mg}$ and dexamethasone $6 \mathrm{mg}$. Heart rate, ECG, oxygen saturation, temperature and BP was monitored. Intraopertive heart rate and oxygen saturation were in the range of 140-170 per minute and $97-99 \%$, respectively.

In subsequent evaluations, contrast enhanced CT-scan thorax showed absence of right bronchus and pulmonary parenchyma with normal hyper-inflated left lung extending anteriorly across midline to right, and slightly posterior deviation of trachea. In the absence of any other pathology and $\mathrm{FB}$, the diagnosis of milk aspiration leading to acute respiratory distress in a patient with unilateral lung agenesis was made. After 5 days of treatment child was discharged from hospital.

\section{Discussion}

Pulmonary agenesis is defined as complete absence of bronchus, parenchyma and vessels. The present case has isolated unilateral lung agenesis of right side without any other associated anomalies.

In the present case, although there was $\mathrm{h} / \mathrm{o}$ breastfeeding a while back, it was not sufficient lead for any diagnosis

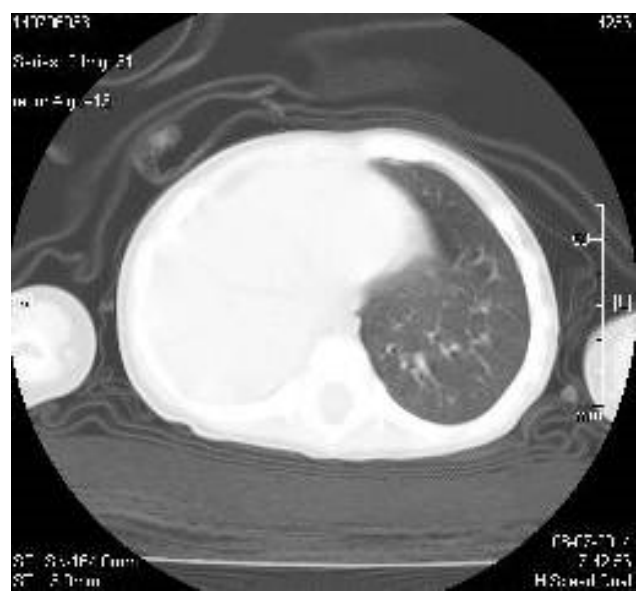

Figure2: Contrast enhanced CT-scan of thorax Showing absence of right bronchus and pulmonary parenchyma

alone or along with the chest X-ray. Radiological features of lung agenesis mimic that of foreign body aspiration and should be considered in unilateral hyperinflation and mediastinal shift.

The challenges of anaesthetic management in such cases include efficient sharing of the small airway for bronchoscopy and anaesthesia, prevention of systemic arterial desaturation, achievement of adequate depth of anaesthesia, minimization of airway secretions, stabilization of hemodynamics, rapid recovery of airway reflexes as well as minimization of sedation beyond the procedure[6]. The underlying pulmonary pathology may pose additional challenges such as compression of airways due to shifting vascular structures, limitation of pulmonary reserve, increased right ventricular afterload, pulmonary hypertension due to absence of right pulmonary artery and predisposition to pulmonary oedema due to reduced residual volume of lung and pulmonary vascular bed [7].

In the present case, flexible bronchoscope was used. Nandalike, et al presented a case of FB aspiration in a child with unilateral lung aplasia where FB was extracted by basket forceps via a flexible bronchoscope after failure to do so with rigid bronchoscopy[8]. Especially in select patients with abnormal airway anatomy, flexible bronchoscopy may be advantageous.

\section{Conclusion}

In summary, congenital pulmonary agenesis is an extremely rare anomaly and may present acutely with severe respiratory distress requiring lifesaving urgent intervention. High index of suspicion and meticulous management in consideration of underlying pathology and 
associated anomalies are warranted for favourable outcome.

\section{References}

1. Bouros D, pare P, Panagou P, Tsintiris K, Siafakas N. Thevaried manifestation of pulmonary artery agenesis inadulthood. Chest 1995; 108(3):670-6.

2. Krivchenya DU, Dubrovin AG, Krivchenya TD, Khursin VN, Lysak CV. Aplasia of the right lung in a 4year-old child: surgical stabilization of the mediastinum by diaphragm translocation leading to complete recovery from respiratory distress syndrome. J Pediatr Surg 2000;35:1499-502

3. Skandalakis JE, Gray SW, Symbas P: The trachea and the lungs. In: Skandalakis JE, Gray SW, editors. Embryology for surgeons. $2^{\text {nd }}$ ed. Baltimore, MD: Williams and Wilkins; 1994.p 429-32.
4. Steve Roberts, Roger E Thornington. Paediatric bronchoscopy. Critical Care and Pain. 2005;2(5):41-44.

5. A. Lorx, L. Valko, I. Penzes. Anaesthesia for interventional bronchoscopy. Eur Respir Mon. 2010;48:18-32.

6. Puneet K. Renu S. Anaesthetic management of a child with congenital lung aplasia with absent pulmonary artery Novel science International Journal of Medical Science (2012, 1 (5): 120-122.

7. Fidkowski CW, Zheng H, Firth P.G. The anesthetic considerations of tracheobronchial foreign bodies in children: a literature review of 12,979 cases Anesth Analg. 2010 Oct; 111 (4):1016-25.

8. Nandalike K, Kessel A, Tripathi S, Sweberg T, Vicencio AG Foreign body aspiration in a child with unilateral lung aplasia Pediatr Crit Care Med. 2011 Sep;12(5):e216-8.

\section{How to cite this article?}

Choudhury J, Routray SS, Biswal D, Rout K, Pradhan K, Mishra D. Unilateral Lung Aplasia Presenting with Acute Respiratory Distress Possibly due to milk aspiration in Young Toddler. Pediatr Rev: Int J Pediatr Res 2014;1(2):55-57. doi:10.17511/ijpr.2014.i02.03 